\title{
Effect of Halide Concentration on the Effectiveness of Banana Peel Waste Inhibitor at $60^{\circ} \mathrm{C}$
}

\author{
Mochamad Puji Widodo, Yohannes Marudut Tua Silaen, Muhammad Faiq Ridho Ahada Kuswara, and \\ Tubagus Noor Rohmannudin
}

\begin{abstract}
Organic inhibitors have been widely studying to be an alternative corrosion prevention because of its abundance and non-hazardous effect to the environment. One of organic inhibitors which is obtained from plant extract is banana (Musa Paradisica) peel, because it has gallocatechin which is a strong antioxidant. Otherwise, inhibition effectiveness from organic compound decreases during increasing of temperature. However, the addition of other substance like halide ion has provided multiple effect of corrosion inhibitor effectiveness. The addition of the halide ions can enhanced the inhibition efficiency of the organic inhibitors. This research highlights the effect of additional halide concentration to the inhibition effectiveness of Musa Paradisica (banana) peel on API $5 \mathrm{~L}$ steel in $3,5 \% \mathrm{NaCl}$ at temperature $6^{\circ} \mathrm{C}$. This inhibition performance is investigated using weight loss measurement and electrochemical measurement. Result shows that the maximum inhibition efficiency was observed with the mixture of $500 \mathrm{ppm}$ banana peel waaste extract and $100 \mathrm{ppm}$ potassium iodide at $60^{\circ} \mathrm{C}$. Also, The blends behaved as mixed type inhibitor. The effectiveness was found to be in order of $\mathrm{KI}>\mathrm{KBr}$ due to the larger ionic radius in iodide ion.
\end{abstract}

Keywords - Banana Peel Waste, Halide Concentration, Organic Inhibitor, Temperature $60^{\circ} \mathrm{C}$.

\section{INTRODUCTION}

$\mathrm{I}$ ron and alloys are one of the most consumed metals for constructional and industrial applications [1] especially carbon and low alloy steels which are the most commonly used material for pipeline in oil and gas industry. Corrosion attack can be happened in mild steel which involves the electrochemical reaction and can cause the degradation and damage to the properties of attacked material. Usually, temperature and salt content are high in oil and gas transmission medium ground medium and drilling fluid [2]. One of the methods to prevent corrosion attack is inhibitor, the use of inhibitors is one of the most practical methods for the surface protection against the corrosive media. So, it is great to examine the corrosion inhibitor resistance in high temperature and salt content.

Scientists have focused their research on green corrosion inhibitors from various plant biomass because of their low operating cost and non-hazardous environmental effect [3][4][5], and [6]. One of plant extract that can be utilized as corrosion inhibitor is banana (Musa Paradisica) peel waste. However, most of banana peel extract was found more efficient in corrosion inhibition of steel than other studied extracts, because gallocatechin is a stronger antioxidant than catechin [7][8]. But, it is known that the effectiveness of organic inhibitor decreased while the temperature increased [9]. Some types of synergetic chemical matter like halide ion when added to organic inhibitor sometimes can increase the efficiency of corrosion inhibitor in high temperature [10].

The objective of this present study is to investigate the effect of halide ions addition namely potassium iodide and potassium bromide in the effectiveness of inhibition efficiency of banana peel waste (BPW) in concentration

Mochamad Puji Widodo, Yohannes Marudut Tua Silaen, Muhammad Faiq Ridho Ahada Kuswara, and Tubagus Noor Rohmannudin are with Departement of Material Engineering, Institut Teknologi Sepuluh Nopember, Surabaya, 60111, Indonesia. E-mail: pujiwidodo639@gmail.com
TABLE 1 .

EFFICIENCY OF EACH MIXTURE ON WEIGHT LOSS TESTING

\begin{tabular}{|c|c|c|c|}
\hline Temperature & Testing & $\begin{array}{c}\text { Corrosion } \\
\text { rate (mmpy) }\end{array}$ & $\begin{array}{c}\text { Efficiency } \\
(\%)\end{array}$ \\
\hline \multirow{10}{*}{$60^{\circ} \mathrm{C}$} & - & 0.9618 & - \\
\hline & 500 ppm BPW & 0.4707 & 51.060 \\
\hline & $\begin{array}{c}500 \mathrm{ppm} \mathrm{BPW} \\
+25 \mathrm{ppm} \mathrm{KI}\end{array}$ & 0.3553 & 63.060 \\
\hline & $\begin{array}{c}500 \mathrm{ppm} \mathrm{BPW} \\
+50 \mathrm{ppm} \mathrm{KI}\end{array}$ & 0.3092 & 67.849 \\
\hline & $\begin{array}{c}500 \mathrm{ppm} \mathrm{BPW} \\
+75 \mathrm{ppm} \mathrm{KI}\end{array}$ & 0.2820 & 70.680 \\
\hline & $\begin{array}{l}500 \mathrm{ppm} \mathrm{BPW} \\
+100 \mathrm{ppm} \mathrm{KI}\end{array}$ & 0.2539 & 73.594 \\
\hline & $\begin{array}{l}500 \mathrm{ppm} \mathrm{BPW} \\
+25 \mathrm{ppm} \mathrm{KBr}\end{array}$ & 0.3766 & 60.846 \\
\hline & $\begin{array}{l}500 \mathrm{ppm} \mathrm{BPW} \\
+50 \mathrm{ppm} \mathrm{KBr}\end{array}$ & 0.3342 & 65.254 \\
\hline & $\begin{array}{l}500 \mathrm{ppm} \mathrm{BPW} \\
+75 \mathrm{ppm} \mathrm{KBr}\end{array}$ & 0.3111 & 67.650 \\
\hline & $\begin{array}{l}500 \mathrm{ppm} \mathrm{BPW} \\
+100 \mathrm{ppm} \mathrm{KBr}\end{array}$ & 0.2919 & 69.644 \\
\hline
\end{tabular}

of 500 ppm against API 5L grade B corrosion in 3,5\% $\mathrm{NaCl}$ solution at high temperature especially at temperature $60^{\circ} \mathrm{C}$. Approximately 36 million tonnes of banana peel is generated every year and this is a potential material for further utilization [11]. Hence, the blends from BPW would be cheap, renewable, non-toxic and abundant.

\section{METHOD}

\section{A. Material Preparation}

Test were performed using steel type API 5L Grade B with dimension $2 \mathrm{~cm} \times 2 \mathrm{~cm} \times 0.3 \mathrm{~cm}$ for both of weight loss and potentiodynamic polarization measurement. Material was polished with silicon carbide abrasive paper from grade 400-1200 then cleaning using aceton and dried in warm air. For potentiodynamic polarization, material was covered with epoxy resin.

\section{B. Inhibitor Preparation}

The fine powder of banana peel was mixed with solvent $70 \%$ methanol and $30 \%$ distilled water for 72 
TABLE 2.

PARAMETER RESULTS ON POLARIZATION TESTING

\begin{tabular}{|c|c|c|c|c|c|c|}
\hline \multirow[b]{2}{*}{ Testing } & \multirow[b]{2}{*}{$\mathbf{E}_{\text {corr }}(\mathbf{V})$} & \multirow{2}{*}{$\begin{array}{l}I_{\text {corr }}(x \\
10^{-6} \\
\left.\mathrm{Am} / \mathrm{cm}^{2}\right)\end{array}$} & \multicolumn{2}{|c|}{ Tafel slope } & \multirow[b]{2}{*}{$\begin{array}{l}\text { Corrosion } \\
\text { Rate (mmpy) }\end{array}$} & \multirow[b]{2}{*}{$\begin{array}{l}\text { Efficiency } \\
(\%)\end{array}$} \\
\hline & & & $\begin{array}{l}b_{a} \\
(\mathrm{mV} / \text { dec })\end{array}$ & $\begin{array}{l}\mathbf{b}_{\mathrm{c}} \\
(\mathrm{mV} / \mathrm{dec})\end{array}$ & & \\
\hline Blank & -0.78757 & 79.41 & 149.02 & 119.8 & 0.9269 & - \\
\hline 500 ppm BPW & -0.78261 & 44.099 & 104.08 & 90.137 & 0.51179 & 44.4667 \\
\hline $500 \mathrm{ppm} \mathrm{BPW}+100 \mathrm{ppm} \mathrm{KBr}$ & -0.76088 & 28.454 & 111.08 & 65.194 & 0.33212 & 64.1682 \\
\hline $500 \mathrm{ppm} \mathrm{BPW} \mathrm{+} 100$ ppm KI & -0.75122 & 11.132 & 103.86 & 113.31 & 0.12993 & 85.9816 \\
\hline
\end{tabular}

TABLE 3 .

PARAMETER RESULTS ON EIS TESTING

\begin{tabular}{lcccc}
\multicolumn{1}{c}{ Testing } & $\mathbf{R s}\left(\mathbf{\Omega c m}^{\mathbf{2}}\right)$ & $\mathbf{R p}\left(\mathbf{\Omega} \mathbf{c m}^{2}\right)$ & $\mathbf{C d l}\left(\boldsymbol{\mu} \mathbf{F} / \mathbf{c m}^{2}\right)$ & \% EI \\
\hline None & 1.834 & 50.08 & 110.92 & - \\
500 ppm BPW & 3.949 & 23.63 & 44.13 & 53.5579 \\
500 ppm BPW + 100 ppm KBr & 4.006 & 44.76 & 46.9 & 54.2187 \\
500 ppm BPW + 100 ppm KI & 4.071 & 30.19 & 53.7 & 54.9496 \\
\hline \hline
\end{tabular}

hours with ratio between powder and solvent is $1: 10$. The extraction method using maceration process.

\section{Weight Loss Measurement}

In weight loss measurement, the prepared material were suspended in $3.5 \% \mathrm{NaCl}$ test solution at $60^{\circ} \mathrm{C}$ for 24 hours with absence and presence inhibitor. Three types of inhibitor that will be used. First only using inhibitor with concentration 500 part per million (ppm). Second, mixture of inhibitor and potassium iodide (KI) with concentration of inhibitor $500 \mathrm{ppm}$ and KI $25 \mathrm{ppm}$, $50 \mathrm{ppm}, 75 \mathrm{ppm}$ and $100 \mathrm{ppm}$. Third, mixture of inhibitor and potassium bromide $(\mathrm{KBr})$ with concentration of inhibitor $500 \mathrm{ppm}$ and KI $25 \mathrm{ppm}, 50$ ppm, $75 \mathrm{ppm}$ and $100 \mathrm{ppm}$. The corrosion rate (mmpy) was calculated using formula (1) :

$$
C R=\frac{K W}{D A T}
$$

where $\mathrm{K}$ is constant, $\mathrm{W}$ is different of weight before and after immersion (gr), D is density ( $\mathrm{gr} / \mathrm{cm} 3)$, A is surface area of immersion material ( $\mathrm{mm}$ ) and $\mathrm{T}$ is time (hour). The inhibition efficiency (IE) of inhibitor was calculated using formula (2) :

$$
\text { IE }(\%)=\frac{C R_{1}-C R_{2}}{C R_{1}} \times 100
$$

where $\mathrm{CR}_{1}$ is corrosion rate in the absence of inhibitor and $\mathrm{CR}_{2}$ is corrosion rate in the presence inhibitor [12].

\section{Electrochemical Measurement}

Electrochemical measurement method is used to know the electrical properties of the inhibitor were conducted with conventional three electrode arrangement. Material specimen with $2 \times 2 \times 0,3 \mathrm{~cm}$ steel specimen size were used as working electrode, graphite rod as counter electrode and saturated calomel electrode (SCE) as reference electrode. The experiment was held in solution for 30 minutes to obtain stable state without stirring in temperature $60^{\circ} \mathrm{C}$.

The Polarization Testing is based on standard (ASTM G5: Potentiostatic and Potentiodynamic Polarization Measurements), and some parameters such as potential (Ecorr), corrosion current density ( $\mathrm{i}_{\text {corr }}$ ), tafel slope and corrosion rate in open circuit potential (OCP) with scan rate $1 \mathrm{mV} \cdot \mathrm{s}^{-1}$ using Corrtest Studio 5 version 5.2 software. The inhibition efficiency (IE) were calculated using formula (3)

$$
\mathrm{IE}(\%)=\frac{i_{\text {corr }}-i^{(1)} \operatorname{corr}}{I_{\text {corr }}} \times 100
$$

where $\mathrm{i}_{\text {corr }}$ and $\mathrm{i}^{(1)}$ corr is corrosion current density without and with inhibitor, respectively [13].

The EIS test uses standard (ASTM G 59: Polarization Resistance Measurements), using frequency intervals of 10000 to $0.1 \mathrm{~Hz}$ with $1 \mathrm{mV}$ amplitude observed in Zview Corrtest Software with some parameters such as Resistance solution (Rs), Resistance polarization (Rp), Coefficient double layer (Cdl) By Nyquist plot. With the efficiency using formula (4) and (5),

$$
\begin{aligned}
& C d l=\frac{1}{2 \pi f R_{p}} \\
& \% E I=\frac{R p_{1}-R p_{2}}{R p_{1}} \times 100
\end{aligned}
$$

where $\mathrm{f}$ is the frequency $(\mathrm{Hz}), \mathrm{Rp}_{1}$ is the polarization resistant without the inhibitor and $\mathrm{Rp}_{2}$ is polarization resistant with the inhibitor [13].

\section{RESULTS AND DISCUSSION}

\section{A. Wieght Loss Measurement}

The corrosion of API 5L grade B steel in 3,5\% $\mathrm{NaCl}$ solution in the absence and presence of banana peel waste (BPW) as inhibitor and the mixture of halides including Potassium Iodide (KI) and Potassium Bromide $(\mathrm{KBr})$ was studied using weight loss measurement at temperature $60^{\circ} \mathrm{C}$. Table 1 gives the values of the corrosion rate and the inhibition efficiency as a function of the presence of $500 \mathrm{ppm}$ inhibitor and halide concentration.

From Table 1, it is known that banana peel waste (BPW) can reduces the corrosion rate and the inhibition efficiency of BPW is increased with the increasing concentration of halide. The reason that banana peel can reduces the corrosion rate can be explained as adsorption of organic matters of the extract on metal surfaces which increased the surface coverage area as well as declining corrosion rate [8]. From the Table 1 it is also known that the addition of halide reduces the corrosion rate of API $5 \mathrm{~L}$ grade $\mathrm{B}$ steel at temperature $60^{\circ} \mathrm{C}$. The maximum inhibition efficiency was found in the addition of 100 ppm halide in Potassium Iodide and Potassium Bromide addition. The results reveal that there is a synergistic effect between inhibitor molecules and halide ions. The addition of KI reduces the corrosion rate larger than the addition of $\mathrm{KBr}$. The order of inhibition efficiency of halide ions were $\mathrm{KI}>\mathrm{KBr}$ with percentage of inhibition efficiency given by the highest concentration of each halide ions $(100 \mathrm{ppm})$ where $\mathrm{KI}(73,594 \%)$ followed by $\operatorname{KBr}(69,645 \%)$. 


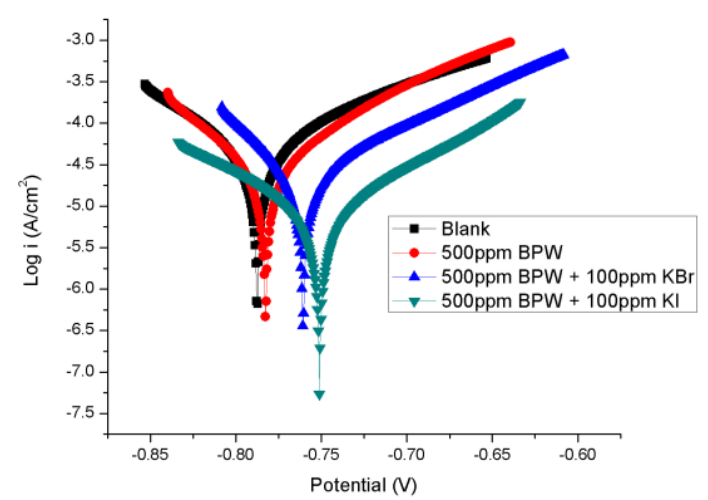

Figure 1. Tafel Polarization Curve in Different Conditions at $60^{\circ} \mathrm{C}$.

The synergistic effect of each halide concentration in all measurement was found to increase in order $\mathrm{Br}^{-}<\mathrm{I}^{-}$, which seems to indicate that the radii of halide ions may influence this effect. The iodide ion has the radius of $1.35 \AA$ is more influence to adsorption than bromide ion which has the radius of $1.14 \AA$. Because of the larger ionic radius, the iodide ion has higher hydrophobicity as compared to the bromide ion [14]. The adsorption of I ions onto the metal surfaces will decrease the hydrophilicity of the metal surfaces, which is likely to promote the adsorption of organic molecule in replace of the water molecules. Thus, the inhibition efficiency of BPW is enhanced to a considerable extent in the presence of $\mathrm{KI}$.

\section{B. Polarization Measurement}

In order to study further about the inhibitor mechanism and the type of inhibitor of BPW at temperature $60^{\circ} \mathrm{C}$, polarization curve experiment was conducted. Figure 1 shows the potentiodynamic polarization behaviour of API 5L grade $\mathrm{B}$ in $3,5 \% \mathrm{NaCl}$ solution in the absence and presence of banana peel waste (BPW) as inhibitor and the mixture of $100 \mathrm{ppm}$ halides.

The corrosion electrochemical parameters, such as corrosion potential (E), cathodic and anodic Tafel slopes $\left(b_{c}\right.$ and $b_{a}$ ) and corrosion current density $(i)$ obtained by extrapolation of Tafel lines and the inhibition efficiency are shown in the Table 2.

It is clear from the figure that the $E_{\text {corr }}$ values were shifted positively in the addition of inhibitor and the combination with $\mathrm{KBr}$ and $\mathrm{KI}$. The result in the Table shows that $i_{\text {corr }}$ decreased when BPW was added with the halide ions. This fact indicating that the addition of halide ions in BPW inhibitor retard corrosion rate of API 5L Grade B sample in $3.5 \% \mathrm{NaCl}$ solution. If the value (Ecorr $=$ Ecorr uninhibited -Ecorr inhibited $)$ is more than $85 \mathrm{mV}$ including anodic or cathodic inhibitor whereas if the value is less than $85 \mathrm{mV}$ including mixing inhibitor [15]. As can be seen from the electrochemical parameters, the largest displacement of corrosion potential of API 5L grade B steel shifted less than $85 \mathrm{mV}$ after BPW and halide ion addition. So, this mixture between BPW and halide ion was classified as mixing inhibitor.

\section{Electrochemical Impedance Spectroscopy Measurement}

The corrosion of API $5 \mathrm{~L}$ grade $\mathrm{B}$ steel in $3,5 \% \mathrm{NaCl}$ solution in the absence and presence of banana peel waste (BPW) as inhibitor and the mixture of halides

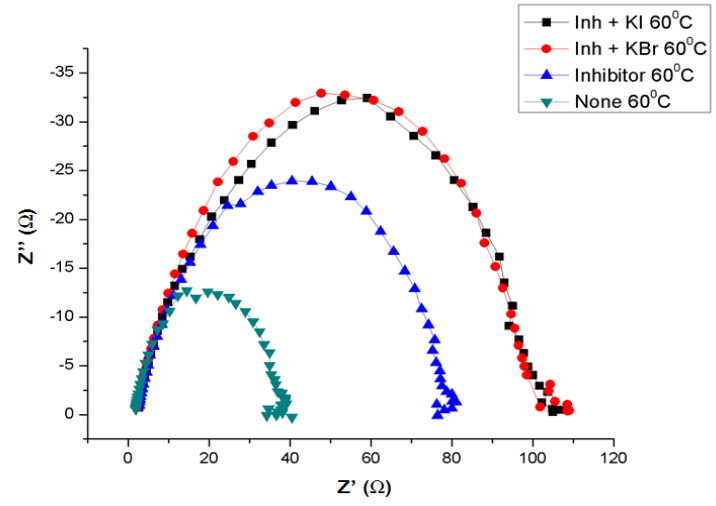

Figure 2. Nyquist Curve EIS Testing in Different Conditions at $60^{\circ} \mathrm{C}$.

including Potassium Iodide (KI) and Potassium Bromide $(\mathrm{KBr})$ was studied using electrochemical impedance spectroscopy measurement at temperature $60^{\circ} \mathrm{C}$ as shown in Figure 2. Table 4 gives the values of some impedance parameters such as Resistance solution (Rs), Resistance polarization (Rp), and Coefficient double layer $(\mathrm{Cdl})$.

The depressed form of semicircles is often referred to as frequency dispersion which has been attributed to surface heterogeneity of structural or interfacial origin such as those found in adsorption processes. The surface heterogeneity usually results from surface roughness, impurities or dislocations, fractalstructures, distribution of activity centers, adsorption of inhibitors, and formation of porous layers [16].

As can be seen in Figure 2 the capacitive reactance arc radius increases gradually after adding the BPW inhibitor, potassium bromide + BPW and potassium iodide + BPW. From Table 3 it is known that the maximum inhibition efficiency occurs in the addition of $100 \mathrm{ppm}$ halide in Potassium Iodide and Potassium Bromide addition where the inhibition efficiency of potassium iodide adding is greater than potassium bromide adding.

The EIS measurement reveals that the mixture of 500 ppm BPW and $100 \mathrm{ppm}$ potassium iodide, the percentage of inhibition efficiency is highest $(54,95 \%)$. The result strongly support the observation that the mixture of $500 \mathrm{ppm}$ BPW and $100 \mathrm{ppm}$ potassium iodide could work best as an inhibitor at $60^{\circ} \mathrm{C}$.

\section{CONCLUSION}

From the result of this study, it is concluded that BPW inhibits the corrosion of API $5 \mathrm{~L}$ grade $\mathrm{B}$ in $3,5 \% \mathrm{NaCl}$ solution at temperature $60^{\circ} \mathrm{C}$. Synergistic effect between BPW and halide ions ( $\mathrm{KI}$ and $\mathrm{KBr}$ ) have been studied. The maximum concentration of adding halide was 100 $\mathrm{ppm}$. The addition of both halide ions synergistically improve the inhibition efficiency of BPW. The synergism was found to be in order of $\mathrm{KI}>\mathrm{KBr}$ due to the larger ionic radius in iodide ion. From Tafel Polarization study, it is revealed that the mechanism of blend was mixing inhibitor.

\section{REFERENCES}

[1] N. Singh, B. Singh, and B. Gaur, "The Role of Metal Cations in Improving the Inhibitive Performance Of Hexamine On The Corrosion Of Steel In Hydrochloric Acid Solution," Corros. Sci, vol. 37, pp. 1005-1019, 1995. 
[2] J. Zhang, X. Sun, Y. Ren, and M. Du, "The Synergistic Effect Between Imidazoline-Based Dissymmetric bisQuaternary Ammonium Salts and Thiourea Against CO2 Corrosion at High Temperature," J Surfact Deterg, vol. 18, pp. 981-987, 2015.

[3] M. Krishnegoweda, V. T. Venkatesha, P. K. M. Krishnegoweda, and S. B. Sivayogiraju, "Acalypha Torta Leaf Extract as Green Corrosion Inhibitor for Mild Steel in Hydrochloric Acid Solution," Ind. Eng. Chem. Res., vol. 52, pp. 722-728, 2013

[4] S. Deng and X. Li, "Inhibition By Ginkgo Leaves Extract of The Corrosion of Steel in $\mathrm{HCl}$ and $\mathrm{H} 2 \mathrm{SO} 4$ Solutions," Corros. Sci, vol. 55, pp. 407-415, 2012.

[5] K. Abiola and A.O. James, "The effect of Aloe Veraextract on Corrosion and Kinetics of Corrosion Process of Zinc in HCl Solution," Corros. Sci, vol. 52, pp. 661-664, 2010.

[6] Y. El-Etre, "Inhibition of Aluminium Corrosion Using Opuntia Extract," Corros. Sci, vol. 45, pp. 2485-2495, 2003.

[7] S. Someya, Y. Yoshiki, and Kazuyoshi Okubo, "Antioxidant Compounds From Bananas (Musa Cavendish)," Food Chem, vol. 79, pp. 351-354, 2002.

[8] S. Ji, S. Anjum, Sundaram, and R. Prakash, "Musa Paradisica Peel Extract As Green Corrosion Inhibitor for Mild Steel in HCl Solution," Corros. Sci., vol. 90, pp. 107-117, 2015.

[9] M. Sangeetha, S. Rajendran, S. Muthumegala, and A. Krishnaveni, "Green Corrosion Inhibitor: An Overview," Zast. Mater., vol. 52, pp. 3-19, 2011.
[10] M. Finsgar and J. Jackson, "Application of Corrosion Inhibitors for Steels in Acidic Media for The Oil And Gas Industry: A Review," Corros. Sci., vol. 86, pp. 17-41, 2014.

[11] T. Vu, C. J. Scarlett, and Q.V. Vuong, "Phenolic Compounds Within Banana Peel And Their Potential Uses: A Review," J. Funct. Foods, vol. 40, pp. 238-248, 2018.

[12] M. Shyamala and P. K. Kasthuri, "The Inhibitory Action of the Extracts of Adathoda vasica, Eclipta alba, and Centella asiatica on the Corrosion of Mild Steel in Hydrochloric Acid Medium: A Comparative Study," Hindawi Publ. Corp., pp. 852-827, 2012.

[13] R. Aslam, M. Mobin, J. Aslam, and H. Lgaz, Sugar Based $N, N$ '-Didodecyl- $N, N$ ' Digluconamideethylenediamine Gemini Surfactant As Corrosion Inhibitor for Mild Steel in $3.5 \% \mathrm{NaCl}$ Solution-Effect of Synergistic KI Additive. Springer Nature Publisher, 2018.

[14] R. Solmaz, M. E. Mert, G. Kardaş, B. Yazici, and M. Erbil "Adsorption and Corrosion Inhibition Effect of 1,1' Thiocarbonyldiimidazole on Mild Steel in H2SO4 Solution and Synergistic Effect of Iodide Ion," Acta Physico-Chimica Sin., vol. 24, no. 7, pp. 1185-1191, Jul. 2008.

[15] M. Ridhwan, A. Rahim, and A.M. Shah, "Synergistic Effect of Halide Ions on the Corrosion Inhibition of Mild Steel in Hydrochloric Acid using Mangrove Tannin," Int. J. Electrochem. Sci, pp. 8091-8104, 2012. 